\title{
Study on the Regulation Mode of Chinese Social Security Fund
}

\author{
Wenbo Li, Hongbo Duan, Xiangzhen Kong \& Xiaobao Ma \\ School of Management, Hebei University, Hebei, China \\ PHD, CAS, UUM, Malaysia \\ E-mail: duanhongbocn@126.com
}

\begin{abstract}
The research is supported by the project of "Over-all Social guarantee System in Urban and Rural Areas: Implement Obstacles, Route Dependence, and System Arrangement" of Hebei Provincial Social Science Fund of 2009 (No. HB09BSH004) and the project of "Study on the Regulation Mode of SOicla Security Fund" of Hebei Provincial Human Resource and Social Security Task of 2010. (Sponsoring information)
\end{abstract}

\begin{abstract}
Based on the running and regulation theories of the current social security fund, the Chinese social security fund and the regulation actuality are deeply analyzed and evaluated in this article. According to national situation of China, following aspects are studied to establish the regulation system of Chinese social security fund with Chinese characteristics, i.e. quickening the construction of the security legislation, developing the supervision content of social security fund, strengthening the operation accounting of social security fund, enhancing the operation benefit and utilizing the auditing supervision, ensuring the social security fund for its specified purposes only, establishing diversification and multi-layer accounting information disclosure system of the social security fund, and strengthening the research of the fund regulation analysis method.
\end{abstract}

Keywords: Social security fund, Regulation, Regulation system of Social security fund, Regulation mode

\section{The regulation actuality of Chinese social security fund}

The social security fund in China includes three parts, and the first one is the social security fund as the basic guarantee, and the second one is the national social security fund managed by the National Council for Social Security Fund, and the third one is the enterprise annuity (i.e. the supplementary pension fund) and the enterprise supplementary medical guarantees paid by the enterprise and individual.

The national social security fund includes the funds from the central finance, the state stock reduction, the equity allocation assets, the capitals raised by other modes, and the funds from the investment income. As the fund hold by the central government, the national social security fund is the important financial repertory and the important material guarantee to stabilize the middle and long-term state finance status, ensure the durative of the social security system, and ensure the implementation of various reform and opening measures. However, the regulation of the social security fund is not powerful, and those occupation and appropriation persons still have opportunity to take advantage of it.

According to relative statistics, from 1996 to 2007, there were above ten billion Yuan of social security fund to be used out of the line. Since 1998, the state has reclaimed about 20 billion Yuan of the fund, and up to the late of 2005, there was 1 billion Yuan which had not been reclaimed. In the period of "the Tenth Five-Year Plan", the Ministry of Labor and Social Security received 96 cases occupying and appropriating the social security fund.

\section{Analysis of the Chinese social security fund regulation mode and problems}

\subsection{Analysis of the Chinese social security fund regulation mode}

There are three patterns of the social security system in the world, i.e. the pay-so-you-go pattern, the completely full funded pattern, and the partly full funded pattern. After tens of years' development and practice, the partly full funded pattern has been gradually thought as an ideal pattern, and it is the direction of the reform of the social security system in many countries.

Based on the original social securities management system, the current social securities fund regulation mode not only holds the trace of the traditional social securities fund management system of China, but embodies the reform result adapting the change of the situation in the new term. China not only confirmed the importance of the social securities fund regulation on the layer of constitution, but constituted and issued many laws and 
regulations about the social securities law and the social securities fund management law, which all have exerted important function to implement the social securities fund regulation and enhance the regulation efficiency. Furthermore, China has established relatively perfect social securities administration regulation institution, and primarily formed the social securities fund regulation system giving priority to the administration regulation of the labor and social security department, and including the finance regulation, the auditing regulation, the bank regulation, the interior control and the social supervision, which could strengthen the supervision of the levy, investment, operation, and granting of the social securities fund.

\subsection{Problems existing in the Chinese social security fund regulation mode}

As viewed from the development of the theory and the practice, the actuality of the Chinese social securities fund regulation could be generalized by "loose supervision and strict control".

Following issues exist in the regulation of the Chinese social securities fund.

(1) The social securities fund regulation legislation is lagged, and the complete social securities fund regulation laws system has not been established.

At present, China has not constituted and issued the social securities law or the social guarantee law, and the social securities fund regulation still lacks in certain legal references. Though there are many laws and regulations about the social securities fund management law or the social securities fund regulation law, but the authority and stabilization of these laws and regulations are less than the law, and the contents are not complete, and most of them are out of season.

(2) The social securities fund regulation excessively depends on the administration measures, and the conflicts among different administration departments have not been solved effectively.

As viewed from the design idea and concrete system arrangement of the regulation mode, the Chinese social securities fund regulation system too relies on the administration measure. The relationships among various administration regulation systems of social securities have not been clarified, and the barriers between higher and lower levels or between different departments still exist in the social securities fund regulation, and the fund regulation is disordered to some extent. When various departments constitute or perform relative policies, they are easy to be influenced by relative departments. Various regions and department only start from their own benefits, so the regulation laws and regulations of the government are hard to be implemented fully. In addition, because of the marginal crossing part formed by original management ranges, conflicts are easy to be formed in the management authorization and policy implementation. Under these factors, the function of the social securities fund is weakened, and the social securities regulation system is inefficiently seriously.

(3) The vacancy of the principal body of the social supervision.

The Chinese social securities fund lacks in efficient social supervision, and the legal guarantee of social supervision is not complete too. As a whole, on various layers from the central to the local government, the social supervision institutions of the social securities have not been established, and the existing social supervision institution only could exert limited function of supervision. In various few regulations, the supervision rights shared by correlative social supervision bodies have not been pointed out. Furthermore, the labor unions and social consensus in China have not determined their own positions independently, and under many situations, their supervision opinions can not work effectively.

\section{Relative suggestions to perfect the Chinese social security fund regulation mode}

3.1 Quickening the construction of the guarantee legislation and developing the regulation content of the social security fund

At present, the social securities develop very quickly, and the function of the government has turned from participating in the industrial economic running to participating in the social public services, and the social commonweal services, the unemployment benefit, and the endowment insurance will be the main content of the government to participate in the resource allocation. In this new situation, based on the uniform securities system, the government should perfect the fund management system by legislation. Some relative department must strengthen the legal construction, stabilize the source channel of the social securities fund by the form of tax law, change the situation that the social securities fund management depends on nothing, and make the social securities to obtain sufficient capital source. When ensuring the stable flow-in of capitals, the regulation department should run relative personnel's legal responsibility for their illegal use of the fund, implement the conversion of the securities management measure from giving priority to the administration to law, and ensure the normal running of the social securities fund, by systematic and standard legal system and perfect and effectively execution institution. 


\subsection{Strengthening the operation accounting of the social security fund and enhancing the operation benefit}

It is very important to strengthen the regulation of the running accounting for enhancing the running benefit of the social securities fund.

First, the capital transit time should be reduced by accounting the transit time of the social securities charge. Second, various agencies should seriously implement relative policies and regulations of the social securities fund management and ensure the legal increment income of the fund. At the same time, the agencies should undertake the responsibility to communicate with the financial department in time for the balanced fund, provide relative opinions about purchasing the national debt and turning to fixed deposit, and achieve the maximum increment of the social securities fund in the current policies. Third, the running of the social securities fund should be supervised. Fourth, foreign advanced experiences should be used for references to train the high-quality composite talents with relative professional knowledge of investment and financing, which could establish good base to enhance the running benefit of the social securities fund, and gradually meet with the international management.

\subsection{Using the auditing supervision to ensure the social security fund for its specified purposes only}

Many departments of the government such as the labor and social securities, the finance, the auditing, and the supervision all have the responsibilities to supervise the income and expenses of the social securities fund. In function, the financial department charges the supervision of the social securities fund, and the auditing department mainly audits the social securities fund and comprehensively analyzes relative data. Because the auditing survey has many advantages such as strong pertinence, short period, solving problems in time, big influence, and significant effect, relative functional departments should reform the auditing and supervision method of the social securities fund, and enhance the pertinence and effectiveness of the auditing and supervision work.

The financial department mainly supervises the fiancé of the social securities fund, supervises whether the social securities charge levied by the collection institution has all entered into the special financial account, supervises whether the agencies have granted various social securities treatments according to the regulations, and supervises whether the agencies disobey the regulation to purchase the national debts and save the fixed deposit for the balanced fund. By the supervision, the social securities fund could be run orderly according to the regulations of income and expenses.

\subsection{Establishing diversification and multi-layer accounting information disclosure system of the social security fund}

The public information disclosure is the important measure to strengthen the social securities fund management and standardize the running of the social securities fund, and the important power to ensure the standard development of the social securities fund. At the same time, after the social securities fund enters into the market, the public disclosed information is the important reference to make investment decisions for investors. Therefore, the social securities trustee institutions should publish the information which could reflect the financial status and management result of the social securities fund, and make most stakeholders could obtain and utilize the financial information about the running of the social securities fund in time. According to the intention of obtaining the accounting information of the social securities fund, the demanders of accounting information could be divided into three sorts, i.e. the common viewers of the social securities fund accounting information, the important viewers of the social securities fund accounting information including the economic policy constitution departments and the asset management companies of the government, and the relative supervision and management departments of the social securities fund accounting information such as the social securities fund management committee, and the auditing bureau. These demanders of demanding the accounting information are not consistent, but they can form the supervision and control of the accounting information to different extents. Therefore, the trustee institutions of the social securities fund should establish the diversification and multi-layer accounting information disclosure system to satisfy different accounting information demanders' regulation demands according to different requirements.

\section{References}

Ba, Shusong, Tan, Yingqing \& Ding, Bo. (2007). Status Quo, Problems and Policy Recommendations for the Supervision of Social Security Fund. Jinan Finance, No.6.

Ba, Shusong, Tan, Yingqing, Zhao, Jing \& Ding, Bo. (2007). Consideration about the Social Security Fund Regulation Frame. Chinese Agricultural Accounting, No.9.

Deng, Xingwen. (2007). Innovation of the Regulation and Investment Mode of Social Security Fund. China Society Periodical, No.4.

Xin, Ling. (2003). Several Misunderstandings about that the Social Security Fund Enters in the Market. Jinan Finance, No.8. 